\title{
ELECTRONIC WORD OF MOUTH (E-WOM) FOURSQUARE: THE NEW SOCIAL MEDIA
}

\author{
Rita, Karyana Hutomo, Natalia \\ Management Department, School of Business Management, BINUS University \\ Jln. K. H. Syahdan No. 9, Palmerah, Jakarta Barat 11480 \\ rita_edula@yahoo.co.id; khutomo@binus.edu; natalia@binus.edu
}

\begin{abstract}
The development of communication technology and Internet-based information encourage the emergence of new changes in the marketing world. Customer-oriented makes it an effective medium for the activities of Word-ofMouth (WOM). In this information era, Word-of-Mouth becomes credible resource in the community. To harness the power of electronic Word-of-Mouth (e-WOM), the company must first identify and understand effectively users of the web to spread their opinions. By using 60 respondents as a source of information and data collection, results of the study found various types of Foursquare users and various motivations that drive them. The first finding of this study revealed six types of Foursquare users, namely: The Gamers, The Existence, The Need Help, The Mayor, The Showoff, and the Angels. The second finding was the type of motivation that Foursquare users are distinguished by category Feature Involvement, Self Satisfaction, Seeking Advice, Economic Incentives, Self Enhancement, and Concern for Other Users. From this study, Self Satisfaction, Self Enhancement, and Concern for Other Users are the motivation type of Foursquare users that give positive contribution to the activities of e-WOM because the three types directly do some sort recommendations or promotions of the places they check-in. Furthermore, Feature Involvement, Seeking Advice, and Economic Incentives are the types that less provide positive contribution to the activities of e-WOM. Advice Seeking and Economic Incentives are the types that the most feel benefits of e-WOM activities through Foursquare. Feature Involvement is the type that does not contribute the most to the activities of e-WOM and do not feel the most benefits of e-WOM activities through Foursquare. This research is expected to help companies that use Foursquare to establish the right business strategy in encouraging e-WOM among Foursquare users.
\end{abstract}

Keywords: e-WoM, Foursquare

\begin{abstract}
ABSTRAK
Perkembangan teknologi komunikasi dan informasi yang berbasis Internet mendorong munculnya perubahan baru dalam dunia marketing. Dengan berfokus pada konsumen (customer oriented) menjadikan media ini efektif bagi kegiatan Word-of-Mouth (WoM). Pada era informasi ini, Word-of- Mouth menjadi salah satu sumber informasi yang cukup dipercaya oleh komunitas pengguna. Untuk memanfaatkan kekuatan dari electronic Word-of-Mouth (e-WoM), perusahaan harus terlebih dahulu mengidentifikasi dan mengerti pengguna web secara efektif untuk menyebarkan pendapat mereka. Dengan menggunakan 60 responden sebagai sumber informasi dan pengumpulan data, hasil penelitian menemukan berbagai macam tipe pengguna Foursquare dan motivasi yang mendorong para pengguna Foursquare tersebut. Hasil pertama temuan penelitian ini mengungkapkan enam tipe pengguna Foursquare, yaitu: The Gamers, The Existence, The Need Help, The Mayor, The Show-off, dan The Angels. Temuan kedua adalah tipe motivasi pengguna Foursquare yang dibedakan berdasarkan kategori Feature Involvement, Self Satisfaction, Advice Seeking, Economic Incentives, Self Enhancement, dan Concern for Other Users. Dari penelitian ini, tipe Self Satisfaction, Self Enhancement, dan Concern for Other Users merupakan motivasi tipe pengguna Foursquare yang memberikan kontribusi positif terhadap kegiatan e-WoM karena ketiga tipe tersebut secara langsung melakukan semacam rekomendasi atau promosi mengenai tempat mereka check-in. Selanjutnya tipe Feature Involvement, Advice Seeking, dan Economic Incentives merupakan tipe yang kurang memberikan kontribusi positif terhadap kegiatan eWoM. Tipe Advice Seeking dan Economic Incentives merupakan tipe yang paling merasakan manfaat dari kegiatan eWoM melalui Foursquare. Tipe motivasi Feature Involvement merupakan tipe yang paling tidak berkontribusi terhadap kegiatan e-WoM dan paling tidak merasakan manfaat dari kegiatan e-WoM melalui Foursquare. Penelitian ini diharapkan dapat membantu perusahaan yang menggunakan Foursquare untuk menetapkan strategi bisnis yang tepat dalam mendorong e-WoM di antara pengguna Foursquare.
\end{abstract}

Kata kunci: e-WoM, Media Sosial, Foursquare 


\section{PENDAHULUAN}

Perkembangan teknologi komunikasi dan informasi yang berbasis Internet mendorong munculnya perubahan baru dalam dunia marketing. Dengan berfokus pada konsumen (customer oriented) menjadikan media ini efektif bagi kegiatan Word-of-Mouth (WoM). Penelitian Perusahaan Public Relation Gollin Haris tahun 2008 menunjukkan bahwa peran word-of-mouth adalah paling signifikan terhadap sumber-sumber informasi yang dapat dipercaya oleh seseorang.

Dalam dunia bisnis word-of-mouth adalah tindakan konsumen memberikan informasi kepada konsumen lain dari seseorang kepada orang lain (antarpribadi) secara nonkomersial baik merek, produk maupun jasa. Word-of-mouth menjadi media yang paling kuat dalam mengomunikasikan produk atau jasa kepada dua atau lebih konsumen (Hasan, 2010). Word-of-mouth merupakan sebuah proses konsumen yang memiliki suatu pengalaman mengenai suatu produk atau jasa berdasarkan pendapat atau pandangan mereka masing-masing kepada orang lain baik positif maupun negatif (Swarbooke \& Horner, 2007).

Motif dari e-WoM sendiri berbeda dengan motif dari WoM karena dipengaruhi kebutuhan sosial masyarakat yang dinamis, perkembangan teknologi informasi, perkembangan media baru, dan lain-lain. Motif e-WoM menurut Hennig-Thurau, et al. (2004), adalah: "concern for other consumer, desire to help the company, social benefits received, exertion of power over the company, postpurchase advice seeking, self-enhancement, economic rewards, convenience in seeking redress, hope that platforms operator will serve as a moderator, expression of positive emotions, venting of negative feelings." Oleh karena itu, untuk memanfaatkan kekuatan dari electronic Word-of-Mouth (e-WoM), perusahaan harus terlebih dahulu mengidentifikasi dan mengerti siapa yang menggunakan web secara efektif untuk menyebarkan pendapat mereka, membuat berita sendiri, atau untuk mengguncang suatu perusahaan (Cakim, 2010). Saat ini, salah satu media yang paling banyak digunakan sebagai media eWoM yaitu situs jaringan sosial seperti Facebook, Twitter, MySpace, Friendster, Foursquare, dll. Orang-orang yang bergabung dalam salah satu komunitas jaringan sosial tersebut saling berbagi pengalaman dan pengetahuan mengenai berbagai macam hal.

Dengan demikian tanpa disadari kehidupan masyarakat sekarang telah mengalami perubahan. Berdasarkan analisis dari banyak sosiolog dan ahli komunikasi marketing, dapat dilihat bahwa faktor terbesar yang mengubah kehidupan masyarakat dunia sekarang ini adalah jaringan sosial (social media). Jaringan sosial menjadi sangat penting baik dalam kehidupan pribadi maupun proses bisnis. Jaringan sosial mampu bersaing dengan berbagai media komunikasi lainnya, bahkan memberikan dampak yang tidak pernah dibayangkan sebelumnya (CreasionBrand, 2011).

Jaringan sosial online merupakan suatu bentuk dari komunitas yang dilakukan secara online dan menghubungkan anggota dari komunitas tersebut di mana pun dan kapan pun mereka berada. Individu yang bergabung dalam komunitas tersebut dapat terpengaruh lingkungan jaringan sosial mereka dengan kejadian-kejadian yang berlangsung di sekitar lingkungan mereka. Oleh karena itu, jaringan sosial online ini menjadi media baru atau ladang bagi pebisnis untuk melakukan kegiatan marketing.

Foursquare adalah sebuah situs web jaringan sosial berbasis lokasi dengan menggunakan GPS yang didukung oleh Google Maps. Foursquare menawarkan kelebihan agar pengguna dapat berbagi informasi tentang keberadaannya atau tempat-tempat yang dikunjungi. Dengan melakukan check-in di suatu tempat menggunakan situs web mobile, pesan teks, atau aplikasi perangkat khusus, kemudian Foursquare akan menunjukkan lokasi. Bahkan dengan sering melakukan check-in, pengguna akan mendapatkan reward/point. Di samping itu pengguna dapat saling bertukar pikiran dan juga berkomentar tentang tempat yang pengguna kunjungi lewat Foursquare. 
Layanan Foursquare ini diciptakan oleh Dennis Crowley dan Naveen Selvadurai. Mereka bertemu pada 2007 saat bekerja di kantor yang sama namun pada perusahaan yang berbeda di kota New York. Diawali dari meja kerja Dennis di New York's East Village, keduanya mulai membangun versi pertama Foursquare pada musim gugur 2008 dan diluncurkan di Austin, Texas pada Maret 2009.

Pengguna dapat memilih untuk check-in atau posting pada akun di Twitter dan Facebook atau keduanya. Dalam versi 1.3 pada aplikasi iPhone, Foursquare mengaktifkan Push-notification untuk teman yang update atau yang juga disebut dengan Pings. Pengguna juga bisa mendapatkan lencana dengan check-in di lokasi tag tertentu berdasarkan frekuensi check-in atau pola lainnya, seperti: waktu check-in. Pengguna dapat membuat suatu daftar To-do untuk pengguna pribadi dan dapat menambahkan Tips agar pengguna lain membaca Tips. Biasanya, Tips berfungsi sebagai sarana untuk hal-hal besar, misal: untuk melakukan sesuatu, melihat sesuatu, atau makan di lokasi tertentu.

Foursquare dimulai pada 2009 dengan ketersediaan lokasi check-in yang sangat terbatas, yaitu; hanya 100 wilayah metro di seluruh dunia. Namun pada bulan Januari 2010, Foursquare mengubah model lokasi sehingga memungkinkan pengguna untuk check-in dari setiap lokasi di seluruh dunia. Pengguna Foursquare saat ini sudah mencapai lebih dari 4 juta orang di seluruh dunia. Foursquare dapat diakses dengan menggunakan iPhone, Android WebOs, Windows Phone 7, dan aplikasi BlackBerry.

Motif e-WoM menurut Hennig-Thurau, et al. (2004), dibagi menjadi 11 yaitu: Concern for Other Consumer, Desire to help the Company, Social Benefits Received, Exertion of Power Over the Company, Post-Purchase Advice Seeking, Self-enhancement, Economic Rewards, Convenience in Seeking Redress, Hope that Platforms Operator will Serve as a moderator, Expression of Positive Emotions, dan Venting of Negative Feelings. Penelitian ini membahas tentang motif e-WoM tersebut dalam aplikasinya di dunia social media, yaitu pengguna social media berbasis lokasi: Foursquare. Motif e-WoM berdasarkan penelitian oleh Hennig-Thurau, et al. (2004) dilakukan pada media webbased opinion platforms. Oleh karena itu penelitian mendefinisikan kembali motif e-WoM dalam aplikasinya pada social media Foursquare. Di samping perlunya mengetahui motif e-WoM dalam social media dan tipe pengguna Foursquare, perlu juga diteliti manfaat dari kegiatan e-WoM dalam social media Foursquare untuk pengembangan strategi bisnis. Menurut data dari Foursquare Labs (2012, Januari), member dari pengguna Foursquare sudah mencapai 15 juta pengguna di seluruh dunia dengan 1,5 milyar check-in lokasi setiap harinya dan lebih dari 75.000 merchant di seluruh dunia yang menggunakan fasilitas Foursquare untuk bisnisnya. Namun karena penelitian e-WoM dalam lingkup social media berbasis GPS ini masih minim jumlahnya; dan masih jarangnya penelitian mengenai penggunaan social media berbasis GPS ini dalam mendorong e-WoM di antara penggunanya dan bermanfaat bagi bisnis yang menggunakan social media ini, maka penelitian ini perlu diperdalam lagi terutama dalam studi kasusnya di Indonesia.

Tujuan dan manfaat penelitian ini adalah untuk mencari dan mengeksplorasi tipe-tipe pengguna Foursquare, mencari dan mengeksplorasi motif-motif pengguna Foursquare, dan mengekplorasi manfaat kegiatan e-WoM dalam Social Media Foursquare untuk pengembangan strategi bisnis. Sedangkan urgensi penelitian, melalui penelitian ini, yang pertama diharapkan adalah mengeksplorasi tipe pengguna Foursquare, kemudian mengeksplorasi motif pengguna Foursquare dalam melakukan check-in. Dengan mengetahui tipe pengguna Foursquare dan motif yang mendasari pengguna untuk melakukan check-in, penelitian ini diharapkan dapat memberikan gambaran kepada pebisnis sejauh mana efektivitas penggunaan kegiatan e-WoM melalui media Foursquare.

\section{Tinjauan Pustaka}

Menurut Engel, Blackwell, dan Miniard (1995), pemahaman terhadap perilaku konsumen mencakup pemahaman terhadap tindakan yang langsung dilakukan oleh konsumen dalam 
mendapatkan, mengonsumsi, dan menghabiskan produk dan jasa termasuk proses keputusan yang mendahului dan mengikuti tindakan tersebut. Perilaku konsumen merupakan studi tentang cara individu, kelompok, dan organisasi serta proses yang dilakukan untuk memilih, mengamankan, menggunakan, dan menghentikan produk, jasa, pengalaman, dan ide untuk memuaskan kebutuhannya dan dampaknya terhadap konsumen dan masyarakat (Hawkins et al). Dengan demikian studi perilaku konsumen itu mencakup bidang yang lebih luas, karena termasuk didalamnya juga mempelajari dampak dari proses dan aktivitas yang dilakukan konsumen terhadap konsumen lain maupun masyarakat.

Pembelian konsumen sangat dipengaruhi oleh karakteristik budaya, sosial, pribadi, dan psikologis (Kotler \& Armstrong, 2008). Biasanya pemasar tidak dapat menggendalikan faktor-faktor semacam itu, tetapi mereka harus memperhitungkannya. Faktor budaya mempunyai pengaruh yang luas dan mendalam pada perilaku konsumen. Pemasar harus memahami peran yang dimainkan oleh budaya, subbudaya, dan kelas sosial pembeli. Perilaku konsumen juga dipengaruhi oleh faktor-faktor sosial, seperti kelompok referensi, keluarga, serta peran dan status sosial konsumen. Keputusan pembeli juga dipengaruhi karakteristik pribadi seperti usia dan tahap siklus hidup pembeli, pekerjaan, situasi ekonomi, gaya hidup, serta kepribadian dan konsep diri. Selanjutnya pilihan pembelian seseorang dipengaruhi oleh empat faktor psikologis utama: motivasi, persepsi, pembelajaran, serta keyakinan dan sikap.

Kelompok referensi (reference group) didefinisikan sebagai individu atau kelompok yang berfungsi sebagai titik perbandingan atau referensi bagi individu lain dalam pembentukan nilai-nilai, sikap atau tuntunan untuk perilaku tertentu. Konsep dasar ini memberikan suatu perspektif yang berharga dalam memahami pengaruh orang lain terhadap kepercayaan, sikap, dan perilaku konsumsi individual. Dari perspektif pemasaran, kelompok referensi merupakan kelompok yang berfungsi sebagai kerangka atau referensi bagi individu dalam keputusan pembelian maupun konsumsi (Schiffman \& Kanuk, 2000).

Kelompok referensi yang memengaruhi nilai-nilai dan perilaku umum individu disebut kelompok referensi normatif. Contoh dari kelompok referensi normatif bagi seorang anak adalah orangtuanya yang memainkan peran penting dalam membentuk nilai-nilai dan perilaku umum anak tersebut sebagai seorang konsumen. Sedangkan kelompok referensi yang berfungsi sebagai benchmark untuk sikap atau perilaku tertentu disebut kelompok referensi komparatif. Kelompok ini bisa saja keluarga maupun tetangga yang gaya hidupnya dikagumi dan ingin ditiru.

Pengertian kelompok referensi mengalami perkembangan dari waktu ke waktu. Kelompok referensi dari yang dulunya didefinisikan secara sempit yang hanya melibatkan kelompok yang berinteraksi secara langsung, kini konsep tersebut telah meluas. Perluasan tersebut melibatkan baik individu maupun kelompok yang memiliki interaksi secara langsung maupun interaksi secara tidak langsung. Kelompok referensi tidak langsung ini terdiri dari individu atau kelompok yang di dalamnya individu tidak memiliki kontak langsung, seperti bintang film, atlet, tokoh politik, atau bintang televisi (Schiffman \& Kanuk, 2000).

Pada dasarnya seseorang bergabung dengan sebuah kelompok referensi untuk tiga alasan, yaitu: untuk mendapatkan pengetahuan yang berharga, untuk mendapatkan penghargaan atau menghindari hukum, dan untuk mendapatkan makna yang digunakan untuk membangun, memodifikasi, atau memelihara konsep pribadi mereka. Salah satu jenis pengaruh yang diberikan oleh kelompok referensi adalah pengaruh informasional dengan informasi yang diberikan berguna bagi pencari informasi. Informasi dapat disajikan secara langsung baik secara verbal atau melalui demonstrasi langsung. Seseorang cenderung lebih terpengaruh oleh kelompok referensi jika informasi yang diberikan dianggap sahih dan relevan pada permasalahan yang dihadapi, dan sumber yang memberikan informasi tersebut dianggap dapat dipercaya. Proses kelompok referensi menyampaikan 
sumber-sumber informasi yang dapat dipercaya berdasarkan pengalaman mereka ini disebut juga dengan Word-of-Mouth (WoM).

\section{Word-of-Mouth (WoM)}

Dalam dunia bisnis word-of-mouth adalah tindakan konsumen memberikan informasi kepada konsumen lain dari seseorang kepada orang lain (antarpribadi) secara nonkomersial baik merek, produk maupun jasa. Word-of-mouth menjadi media yang paling kuat dalam mengomunikasikan produk atau jasa kepada dua atau lebih konsumen (Hasan, 2010). Menurut Swarbooke dan Horner (2007), word-of-mouth merupakan sebuah proses konsumen yang memiliki suatu pengalaman mengenai suatu produk atau jasa berdasarkan pendapat atau pandangan mereka masing-masing kepada orang lain baik positif maupun negatif. Dalam word-of-mouth konsumen yang memutuskan tentang sesuatu yang sangat berharga untuk dibicarakan. Konsumen yang telah memiliki pengalaman unik tentang produk, jasa, dan merek dari perusahaan tertentu ini, cenderung akan memasukkan produk, jasa, dan merek tersebut ke agenda percakapan. Mereka secara sadar atau tanpa sadar mengungkapkannya kepada orang lain secara lisan (word-of-mouth) dalam berbagai kesempatan.

Beberapa alasan yang membuat WoM dapat menjadi sumber informasi yang kuat dalam memengaruhi keputusan pembelian adalah sebagai berikut. Pertama, WoM adalah sumber informasi yang independen dan jujur (ketika informasi datang dari seorang teman itu lebih dapat dipercaya karena tidak memiliki asosiasi dengan orang dari perusahaan atau produk). Kedua, WoM sangat kuat karena memberikan manfaat kepada yang bertanya langsung tentang produk melalui pengalaman teman dan kerabat. Ketiga, WoM disesuaikan dengan orang-orang yang tertarik di dalamnya, seseorang tidak akan bergabung dengan percakapan, kecuali mereka tertarik pada topik diskusi. Keempat, WoM menghasilkan media iklan informal. Kelima, WoM dapat dimulai dari satu sumber tergantung kekuatan influencer dari jaringan sosial itu menyebar dengan cepat dan secara luas kepada orang lain. Keenam, WoM tidak dibatasi oleh ruang atau kendala lainnya seperti ikatan sosial, waktu, keluarga, atau hambatan fisik lainnya.

Dichter (1996) membagi tipologi motif menjadi empat kategori utama dari positif word-ofmouth. Namun kelemahan dari motif Dichter ini tidak menjelaskan lebih lanjut detail informasi mengenai keempat tipologi tersebut. Product-involvement, yaitu konsumen merasa yakin mengenai suatu produk sehingga membangun suatu dorongan untuk melakukan sesuatu seperti merekomendasikan kepada pihak lain. Self-involvement, yaitu produk berfungsi sebagai alat pembicara dapat memuaskan kebutuhan emosional tertentu. Other-involvement, yaitu kegiatan word-of-mouth memberikan kebutuhan untuk memberikan sesuatu kepada penerima. Message-involvement merujuk kepada diskusi mengenai apa yang distimuli oleh iklan, komersial atau hubungan masyarakat.

Komunikasi WoM dapat muncul melalui berbagai macam media seperti, telepon, email, mailing list dan berbagai alat komunikasi. Sebagai sumber rekomendasi dibagi menjadi dua, yaitu: personal dan impersonal yang dikenal sebagai sarana WoM. Teman, keluarga, dan kenalan merupakan sumber personal dari rekomendasi; sedangkan kolom berita, artikel, komentar dari jurnalis, konsumen, dan para ahli merupakan sumber rekomendasi impersonal dari WoM (Goyette and Ricard, 2010).

Engel, Blackwell, dan Miniard (1993) kemudian melakukan modifikasi terhadap tipologi dari Dichter dengan mengganti beberapa nama kategori dan memperkenalkan kategori baru yaitu dissonance reduction. Mereka berusaha memunculkan sisi negatif dari word-of-mouth (tidak hanya positif seperti yang dikemukakan oleh Dichter). Involvement adalah level dari daya tarik atau keterlibatan dalam suatu topik di bawah pertimbangan berfungsi untuk merangsang diskusi. Selfenhancement adalah rekomendasi yang memungkinkan orang untuk mendapatkan perhatian, menyarankan status, memberikan impression mengenai penyampaian di dalam informasi dan menegaskan superioritas. Concern for others adalah keinginan untuk membantu teman atau kerabat untuk membuat keputusan pembelian yang lebih baik. Message intrigue, yaitu ingin membicarakan 
mengenai suatu iklan. Dissonance reduction menurunkan keraguan untuk mengikuti keputusan pembelian.

Sundaram, Mitra, dan Webster (1998) mengembangkan kategori yang dikemukan oleh Dichter dan Engel, dkk. Empat identifikasi pertama mengacu pada motif positif word-of-mouth (altruism, product-involvement, self-enhancement, helping company). Empat identifikasi berikutnya mengacu pada motif negatif word-of-mouth (altruism, anxiety reduction, vengeance, advice seeking). Altruism (positif WoM) adalah kegiatan untuk melakukan sesuatu untuk orang lain tanpa mengharapkan adanya imbalan. Product-involvement merupakan keinginan pribadi terhadap suatu produk, kesenangan akan suatu produk atau kegunaan produk. Self-enhancement meningkatkan image di antara para konsumen dengan menampilkan diri sebagai pembeli yang pandai. Helping company adalah keinginan untuk membantu perusahaan. Altruism (negatif WoM), yaitu untuk mencegah orang lain dari pengalaman terhadap masalah yang dihadapi. Anxiety reduction meredakan kemarahan, kecemasan, dan frustasi. Vengeance adalah untuk membalas perusahaan sehubungan dengan pengalaman penggunaan yang negatif. Advice seeking adalah mendapatkan nasihat dari masalah yang dihadapi.

Shinnar, Young, dan Meana (2004) mengembangkan teori yang menyatakan bahwa motivasi WoM dibagi menjadi 2, yaitu: motivasi intrinsik dan motivasi ekstrinsik. Motivasi intrinsik didefinisikan sebagai suatu perilaku yang muncul untuk kepentingan diri sendiri daripada mendapatkan sesuatu atau social reward. Motivasi instrinsik ini didorong oleh beberapa faktor: selfinvolvement didorong oleh keinginan pribadi (kepentingan pribadi); self-confirmatory didorong oleh keinginan bahwa pribadi merupakan bagian dari perusahaan; other involvement; keinginan untuk menolong atau membagikan keuntungan/pengalaman. Motivasi ekstrinsik didefinisikan sebagai suatu perilaku yang muncul karena dorongan dari luar. Faktor yang mendorong motivasi ini adalah incentives.

\section{Electronic Word-of-Mouth (e-WoM)}

Tradisional word-of-mouth (offline) memegang peranan penting dalam keputusan pembelian konsumen. Namun seiring dengan perkembangan Internet, saat ini WoM telah berkembang menjadi electronic word-of-mouth. Menurut Hennig-Thurau (2004), electronic Word-of-Mouth (e-WoM) communication merujuk pada pernyataan positif atau negatif dari potensial, aktual atau konsumen pendahulu mengenai suatu produk atau perusahaan via Internet.

Motif dari e-WoM sendiri berbeda dengan motif dari WoM karena dipengaruhi oleh kebutuhan sosial masyarakat yang dinamis, perkembangan teknologi informasi, perkembangan media baru, dan lain-lain. Motif e-WoM menurut Hennig-Thurau (2004), adalah: concern for other consumer, desire to help the company, social benefits received, exertion of power over the company, post-purchase advice seeking, self-enhancement, economic rewards, convenience in seeking redress, hope that platforms operator will serve as a moderator, expression of positive emotions, venting of negative feelings. Oleh karena itu, untuk memanfaatkan kekuatan dari electronic word-of-mouth (eWoM), perusahaan harus terlebih dahulu mengidentifiksi dan mengerti siapa yang menggunakan web secara efektif untuk menyebarkan pendapat mereka, membuat berita sendiri atau untuk mengguncang suatu perusahaan (Cakim, 2010).

Khususnya, web telah menciptakan kesempatan kepada electronic word-of-mouth (e-WoM) berkomunikasi melalui berbagai macam media seperti forum diskusi, electronic bulletin board, newsgroup, blog, dan social networking (Goldsmith, 2006). Saat ini, salah satu media yang paling banyak digunakan sebagai media e-WOM yaitu situs jejaring sosial seperti Facebook, Twitter, MySpace, Friendster, Foursquare, dll. Orang-orang yang bergabung dalam salah satu komunitas jaringan sosial tersebut saling berbagi pengalaman dan pengetahuan mengenai berbagai macam hal. 
Menurut Fowler dan Christakis (2008), social networks terdiri dari 2 elemen, individual (nodes) dan hubungan sosial (relationship). Ketika hubungan terjalin, maka akan tergambar suatu jaringan. Didalam jaringan tersebut, seseorang akan dapat menggambarkan jarak antar dua orang. Ide dasar dari analisa social networking adalah bagaimana individu dapat terpengaruh oleh lingkungan jaringan sosial dengan kejadian yang terjadi di sekitar lingkungan sekitar mereka.

\section{METODE PENELITIAN}

Metode penelitian kualitatif adalah metode penelitian yang digunakan untuk meneliti pada kondisi objek yang alamiah dengan peneliti adalah sebagai instrumen kunci; teknik pengumpulan data dilakukan secara trianggulasi (gabungan), analisis data bersifat induktif, dan hasil penelitian kualitatif lebih menekankan makna daripada generalisasi (Sugiyono, 2005). Metode penelitian kualitatif akan cocok digunakan untuk meneliti: jika masalah penelitian belum jelas dan masih kabur, memahami makna di balik data yang tampak, memahami interaksi sosial, memahami perasaan orang, mengembangkan teori, memastikan kebenaran data, dan meneliti sejarah perkembangan. Melihat dari uraian tersebut, maka jelas bahwa penelitian ini lebih cocok dengan menggunakan studi kualitatif karena penelitian mengenai Foursquare ini masih sangat jarang. Melalui penelitian kualitatif, peneliti dapat melakukan eksplorasi terhadap suatu objek.

\section{Studi Ethnography}

Kata ethnography berasal dari antropologi yang artinya metode riset yang menggunakan observasi langsung terhadap kegiatan manusia dalam konteks sosial dan budaya sehari-hari. Menurut Maulana (2007), ethnography merupakan suatu studi atau riset tentang perilaku masyarakat atau konsumen yang dipelajari langsung dari habitat atau dari lingkungan natural. Teknik ethnography kini telah banyak digunakan oleh perusahaan besar dan terbukti manfaatnya untuk penciptaan produk baru dan pengembangan merek. Menurut Maulana (2008), kritik yang muncul terhadap metode ini adalah lamanya menyelesaikan sebuah studi karena proses pengumpulan data yang memakan waktu berbulan-bulan. Seiring dengan perkembangan zaman, maka metode ethnography kini telah berkembang dengan dua istilah baru: netnography dan digital ethnography. Netnography adalah studi ethnography yang dikerjakan secara online. Observasi bisa dilakukan dalam diskusi-diskusi di mailing list yang diikuti dengan eksplorasi secara lebih mendalam melalui online chatting dengan responden. Adapun digital ethnography adalah observasi dengan bantuan kamera digital, baik berupa video maupun foto yang digunakan untuk melengkapi data yang dikumpulkan periset.

\section{Hasil Eksplorasi}

Data eksplorasi diperoleh dari hasil wawancara dengan pengguna Foursquare yang ada di Jakarta melalui metode in-depth interview dan usability interview dengan wawancara secara langsung. Data didapat dari hasil pengamatan (observasi langsung) terhadap pengguna Foursquare yang checkin di venue/tempat tertentu. Data pengamatan diperoleh dengan bantuan voice recorder melalui handphone.

\section{Teknik Pengumpulan Data}

Teknik pengumpulan data merupakan langkah yang paling strategis dalam penelitian, karena tujuan utama dari penelitian adalah mendapatkan data. Dalam penelitian kualitatif, pengumpulan data dilakukan pada natural setting (kondisi yang alamiah), sumber data primer, dan teknik pengumpulan data lebih banyak pada observasi berperan serta (participating observation), wawancara mendalam (in depth interview) dan dokumentasi. Menurut Sugiyono (2005) wawancara merupakan pertemuan dua 
orang untuk bertukar informasi dan ide melalui tanya jawab, sehingga dapat dikonstruksikan makna dalam suatu topik tertentu. Wawancara dapat dilakukan secara individu atau grup. Penelitian dilakukan dengan memilih tipe wawancara: Wawancara terstruktur digunakan sebagai teknik pengumpulan data, jika peneliti atau pengumpul data telah mengetahui dengan pasti tentang informasi apa yang akan diperoleh. Oleh karena itu dalam melakukan wawancara, pengumpul data telah menyiapkan instrumen penelitian berupa pertanyaan-pertanyaan tertulis yang alternatif jawabannya pun telah dipersiapkan. Jenis wawancara semiterstruktur sudah termasuk dalam kategori in-deptinterview, yang dalam pelaksanaannya lebih bebas jika dibandingkan dengan wawancara tersturktur. Tujuan dari wawancara jenis ini adalah untuk menemukan permasalahan secara lebih terbuka, yang pihak diajak wawancara diminta pendapat dan ide-idenya. Wawancara tidak terstruktur adalah wawancara yang bebas, dengan peneliti tidak menggunakan pedoman wawancara yang telah tersusun secara sistematis dan lengkap untuk pengumpulan datanya.

Teknik riset kualitatif pertama adalah wawancara tidak terstruktur dan wawancara semiterstruktur yang lebih banyak digunakan dalam riset kualitatif dengan mempertimbangkan faktorfaktor: tergantung dari berkembangnya dialog antara responden dan pewawancara, dibutuhkan kreativitas pewawancara, menggunakan kemampuan dari pewawancara untuk mendapatkan lebih banyak bentuk data, menggunakan pengalaman dari pewawancara untuk mendapatkan kejelasan yang lebih dalam dan menggali jawaban lebih lengkap. Teknik riset kualitatif yang kedua adalah usability interview yang merupakan gabungan antara observasi langsung dan wawancara untuk melihat proses dari penggunaan produk. Teknik ini lebih cocok digunakan pada produk-produk berteknologi karena responden terkadang kesulitan untuk mengikuti prosedur penggunaan suatu produk, langkahlangkah/tahapan yang harus diikuti, dan lain-lain. Teknik ini digunakan dengan cara duduk bersampingan dengan responden untuk membantu langkah penggunaan produk.

Wawancara baik yang dilakukan dengan face-to-face maupun dengan menggunakan telepon akan selalu terjadi kontak pribadi. Oleh karena itu pewawancara perlu memahami situasi dan kondisi dalam memilih waktu dan tempat yang tepat dalam melakukan wawancara. Jika wawancara dipaksakan pada kondisi yang responden sedang sibuk, sedang memiliki masalah berat, sedang sakit atau sedang marah, pewawancara harus hati-hati dalam melakukan wawancara. Jika dipaksakan, data yang didapat menjadi tidak valid dan akurat.

\section{Teknik Sampling}

Pengambilan sampel dilakukan secara nonprobability sampling dengan teknik purposive sampling. Pengambilan sampel dilakukan dengan nonprobability sampling karena setiap anggota tidak mempunyai kesempatan yang sama untuk diseleksi (Cooper \& Schlinder, 2003). Sedangkan purposive sampling dimaksudkan karena sampel yang digunakan dalam penelitian dipilih dengan sengaja berdasarkan kriteria yang ditetapkan oleh peneliti (Sekaran, 2000). Untuk mendefinisikan responden secara lebih jelas, peneliti menggunakan dua kriteria responden, yaitu: responden merupakan pengguna aktif Foursquare yang berdomisili di Jakarta, responden memiliki pendidikan minimal Strata 1.

\section{HASIL DAN PEMBAHASAN}

Setelah melalui wawancara mendalam (in depth interview) guna proses pencarian dan pengumpulan data, ditemukan gambaran mengenai karakteristik tipe dan motif pengguna Foursquare. Hasil temuan dan analisis ini diharapkan dapat membantu perusahaan yang ingin menggunakan Foursquare sebagai salah satu media promosi, sehingga dapat menjangkau pasar lebih luas dengan biaya yang minimal. 


\section{Karakteristik Pengguna Foursquare}

Menurut Kelleher dan Helkkula (2010) tipe-tipe pengguna Foursquare menunjukkan karakteristik berdasarkan tingkat pengetahuan terhadap Foursquare yang disebut expertise dan penerapan manfaat Foursquare yang disebut passionate. Karakteristik tersebut dapat dibagi lagi menjadi empat bagian, yaitu: passionate expert users, dispassionate expert users, passionate novice users, dan dispassionate novice users. Penggunaan istilah expert ini dimaksudkan bahwa pengguna Foursquare merupakan pengguna yang mengerti seluk-beluk Foursquare dan berpengalaman menggunakan Foursquare. Sebaliknya, istilah novice adalah pengguna Foursquare yang kurang memiliki pengetahuan mengenai Foursquare dan kurang berpengalaman dalam menggunakan Foursquare. Penggunaan istilah dispassionate merujuk pada pengguna Foursquare yang kurang memanfaatkan kelebihan Foursquare dalam penggunaannya. Sebaliknya, istilah Passionate merujuk pada pengguna Foursquare yang sangat memanfaatkan fitur-fitur dan kelebihan Foursquare.

\section{Tipe Pengguna Foursquare}

Tipe The Gamers adalah mereka yang menggunakan Foursquare untuk kegiatan bersenangsenang (having fun) dengan mengumpulkan badge. Badge ini didapatkan jika mereka dapat menyelesaikan suatu misi tertentu. Seperti kutipan narasumber berikut: “Games pada Foursquare sangat menyenangkan, kita bisa check-in di tempat tertentu selama berjam-jam sudah bisa mendapatkan badge dan saya sekarang juga sedang mengejar badge-badge yang lain. Jadi saya akan check-in sesuai dengan misi yang diminta.”

Tipe The Existence adalah mereka yang menggunakan Foursquare agar terlihat eksis dan ingin selalu menginformasikan kepada pengguna lain mengenai kegiatan, kesibukan, maupun perasaan yang sedang dialami. Seperti kutipan salah seorang narasumber berikut: "Kalau ada kesempatan saya selalu check-in di mana pun dan kapan pun, biar orang lain tahu kalau saya sedang apa dan lagi di mana.”

Tipe The Need Help adalah mereka yang menggunakan Foursquare untuk mendapatkan tips, rekomendasi atau masukan mengenai suatu tempat. Seperti kutipan narasumber berikut: "Saya pakai Foursquare kalau saya sedang pergi ke tempat baru dan tidak tahu situasi tempat tersebut. Jadi saya buka Foursquare agar bisa lihat tips-tips yang ditinggalkan oleh orang-orang yang sudah pernah check-in sebelumnya di tempat tersebut. Jadi saya bisa tahu kira-kira situasi di tempat itu.”

Tipe The Mayor adalah mereka yang menggunakan Foursquare untuk menjadi mayor di satu tempat tertentu. Mayor yaitu pengguna yang paling banyak check-in di tempat tersebut. Seperti kutipan narasumber berikut: "Saya check-in menggunakan Foursquare agar nama dan wajah saya sering muncul di tempat itu, sehingga dapat dilihat oleh siapa pun yang juga check-in di tempat tersebut. Itu berarti saya sering datang dan berlangganan ke tempat tersebut.”

Tipe The Show-off adalah mereka yang menggunakan Foursquare untuk pamer (show-off) kepada orang lain karena dengan check-in mereka memberitahukan kepada pengguna lain tempattempat mewah (elite) yang sedang mereka kunjungi. Seperti kutipan narasumber berikut: "Saya pakai Foursquare biar orang lain pada tahu kalau saya sedang berada di tempat mewah dan berkelas."

Tipe The Angels adalah mereka yang selalu meninggalkan tips-tips di tempat mereka check-in dengan menggunakan Foursquare. Alasannya karena ingin membantu mereka yang check-in di tempat mereka check-in. Seperti kutipan narasumber berikut: "Saya kalau sedang check-in di suatu tempat tertentu, selalu berkeinginan untuk memberi tips mengenai tempat itu, agar dapat menjadi masukan bagi orang lain yang akan berkunjung dan check-in di tempat tersebut.” Berdasarkan hasil temuan pengguna Foursquare secara kualitatif, maka ditemukan beberapa tipe yang menonjol pada pengguna tersebut, yaitu: tipe The Gamers dan The Existence. 
Tabel 1 Perbandingan Besarnya Tipe-tipe Pengguna Foursquare

\begin{tabular}{|c|c|c|}
\hline Tipe-tipe & Frekuensi & Persentase $(\%)$ \\
\hline The Gamers & 25 & 42 \\
\hline The Existence & 13 & 21 \\
\hline The Need Help & 8 & 13 \\
\hline The Mayor & 6 & 10 \\
\hline The Show-off & 4 & 7 \\
\hline The Angels & 4 & 7 \\
\hline Total & 60 & 100 \\
\hline
\end{tabular}

Berdasarkan data, maka diketahui bahwa pengguna Foursquare yang terbesar adalah dari tipe The Gamers dengan persentase pengguna adalah 42\% (25 responden). Sedangkan $21 \%$ pengguna berjumlah 13 responden untuk tipe The Existence dan 8 responden dengan $13 \%$ untuk tipe The Need Help. Sebesar 10 \% (6 responden) pengguna adalah dari tipe The Mayor, dan terakhir 7\% pengguna (masing-masing 4 responden) untuk tipe The Show-off dan The Angels. Tabel berikut adalah matriks tipe pengguna Foursquare yang digolongkan berdasarkan karakteristiknya.

Tabel 2 Matriks Tipe-tipe Pengguna Foursquare Berdasarkan Karakteristik

\begin{tabular}{lcccc}
\hline Karakteristik & $\begin{array}{c}\text { Dispassionat } \\
\text { e Expert }\end{array}$ & $\begin{array}{c}\text { Passionat } \\
\text { e Expert }\end{array}$ & $\begin{array}{c}\text { Dispassiona } \\
\text { te Novice }\end{array}$ & $\begin{array}{c}\text { Passionate } \\
\text { Novice }\end{array}$ \\
\hline $\begin{array}{l}\text { The Gamers } \\
\text { The Existence }\end{array}$ & 25 & - & - & - \\
The Need Help & - & - & 13 & - \\
The Mayor & 6 & - & - & 8 \\
The Show-off & - & - & - & - \\
The Angels & - & 4 & - & - \\
\multicolumn{1}{r}{ Total } & 31 & 4 & 17 & - \\
\hline
\end{tabular}

Dari data tabel matriks tersebut, maka dapat diketahui bahwa tipe pengguna yang memiliki karakteristik yang negatif (dispassionate) sebesar 48 responden lebih banyak dibandingkan dengan pengguna yang memiliki karakteristik cenderung positif (passionate) sebesar 12 responden. Sedangkan berdasarkan kemampuan dan keahlian, maka tipe pengguna yang ahli (expert) sebesar 35 responden lebih banyak dari tipe pengguna yang kurang ahli (novice) sebesar 25 responden .

\section{Motivasi Pengguna Foursquare}

Motivasi feature involvement menggunakan Foursquare karena ingin menggunakan fitur-fitur yang ditawarkan oleh Foursquare, misalnya ingin mengumpulkan badge. Seperti pada kutipan narasumber berikut: "Games pada Foursquare sangat menyenangkan, kita bisa check-in di tempattempat tertentu selama berjam-jam sudah bisa mendapatkan badge dan saya sekarang juga sedang mengejar badge-badge yang lain. Jadi saya akan check-in sesuai dengan misi yang diminta.”

Motivasi self satisfaction menggunakan Foursquare didorong oleh keinginan untuk eksistensi atau hanya agar dilihat oleh pengguna lain mengenai keberadaan pengguna. Seperti pada kutipan narasumber berikut: "Kalau ada kesempatan saya selalu check-in di mana pun dan kapan pun, biar orang lain tahu kalau saya sedang apa dan lagi di mana."

Motivasi advice seeking menggunakan Foursquare muncul karena keinginan untuk mencegah perasaan ketakutan tertentu sehingga mencari masukan, tips, atau informasi mengenai suatu tempat untuk mencegah terjadinya kekecewaan. Seperti kutipan narasumber berikut: "Kalau saya check-in 
pakai Foursquare, saya akan membaca tips-tips yang ditinggalkan. Misalnya menu apa yang jadi favorit dan tempat mana yang enak untuk hang out.

Motivasi economic incentives menggunakan Foursquare didorong oleh faktor ekonomi tertentu, misalnya untuk mencari tempat-tempat yang memberikan diskon atau tempat-tempat yang sedang sale atau restoran yang sedang ada penawaran kartu kredit tertentu, dan lain-lain. Seperti kutipan narasumber berikut: "Saya pakai Foursquare kalau saya sedang pergi ke tempat baru dan tidak tahu situasi tempat tersebut. Jadi saya buka Foursquare agar bisa lihat tips-tips yang ditinggalkan oleh orang-orang yang sudah pernah check-in sebelumnya di tempat tersebut. Jadi saya bisa tahu kira-kira situasi di tempat itu."

Motivasi self enhancement menggunakan Foursquare didorong oleh keinginan untuk meningkatkan status sosial, seperti kutipan narasumber berikut: "Saya pakai Foursquare biar orang lain pada tahu kalau saya sedang berada di tempat mewah dan berkelas.”

Motivasi concern for other users menggunakan Foursquare muncul karena keinginan untuk berbagi tips dan informasi kepada pengguna lain. Seperti kutipan narasumber berikut: "Saya kalau sedang check-in di suatu tempat tertentu, selalu berkeinginan untuk memberi tips mengenai tempat itu, agar dapat menjadi masukan bagi orang lain yang akan berkunjung dan check-in di tempat tersebut.”

Tabel berikut merupakan tabel rangkuman pandangan tipe motivasi para pengguna Foursquare dan hubungannya dengan kegiatan e-WoM yang dilakukan.

Tabel 3 Jenis e-WoM Positif dan e-WoM Negatif

\begin{tabular}{lcc}
\hline Motivasi & $\begin{array}{c}\text { Positif } \\
(+)\end{array}$ & $\begin{array}{c}\text { Negatif } \\
(-)\end{array}$ \\
\hline Feature Involvement & - & $\sqrt{ }$ \\
Self Satisfaction & $\sqrt{ }$ & - \\
Advice Seeking & - & $\sqrt{ }$ \\
Economic Incentives & - & $\sqrt{ }$ \\
Self Enhancement & $\sqrt{ }$ & - \\
Concern for Other Users & $\sqrt{ }$ & - \\
\hline
\end{tabular}

Berdasarkan tabel tersebut, bahwa motivasi pengguna Foursquare hubungannya dengan kegiatan e-WoM antara positif dan negatif adalah seimbang. Motivasi yang mendukung kegiatan eWoM ada tiga, yaitu: tipe motivasi Self Satisfaction, Self Enhancement dan Concern for Other Users. Sedangkan tipe motivasi yang kurang mendukung kegiatan e-WoM ada tiga, yaitu: tipe Feature Involvement, Advice Seeking, dan Economic Incentives. Namun tidak tertutup kemungkinan dari ketiga tipe tersebut dapat melakukan kegiatan e-WoM positif baik secara sengaja maupun tidak disengaja.

\section{SIMPULAN}

Setelah melalui eksplorasi dengan menggunakan metode ethnography melalui in-depth interview dan usability interview, maka dapat ditentukan terdapat enam tipe pengguna Foursquare, yaitu: The Gamers, The Existence, The Need Help, The Mayor, The Show-off, dan The Angels. Kemudian dari keenam tipe pengguna Foursquare tersebut dapat dijabarkan berdasarkan tingkat pengetahuan terhadap Foursquare (Expertise) dan Penerapan manfaat Foursquare (Passionate) yang dibagi menjadi empat macam karakteristik. Yang pertama, Dispassionate Expert, tipe yang masuk dalam tipe ini adalah tipe The Gamers dan The Mayor. Tipe ini ahli dalam menggunakan Foursquare 
namun kurang memiliki keinginan untuk menggunakan Foursquare untuk hal-hal bermanfaat. Kedua adalah Passionate Expert, tipe dalam karakteristik ini adalah tipe The Angels karena tipe ini selain ahli dalam menggunakan Foursquare juga memiliki keinginan untuk menggunakan Foursquare untuk halhal bermanfaat. Ketiga, Dispassionate Novice, tipe yang masuk segmen ini adalah tipe The Existence dan The Show-off. Tipe ini kurang ahli dalam menggunakan Foursquare dan kurang memiliki keinginan untuk menggunakan Foursquare untuk hal-hal yang lebih bermanfaat. Keempat, Passionate Novice, tipe yang masuk dalam karakteristik ini adalah tipe The Need Help karena tipe ini masih kurang ahli dalam menggunakan Foursquare namun memiliki keinginan untuk menggunakan Foursquare untuk hal-hal bermanfaat.

Penemuan kedua dalam penelitian ini adalah motivasi pengguna Foursquare yang dibedakan berdasarkan kategori Feature Involvement, Self Satisfaction, Advice Seeking, Economic incentives, Self Enhancement, dan Concern for Other Users. Setelah mendefinisikan motivasi pengguna Foursquare tersebut, maka ditemukan dua jenis kegiatan e-WoM berdasarkan motivasi pengguna Foursquare. Pertama, e-WoM yang positif dengan motivasi yang ditemukan dalam penelitian ini mendukung kegiatan e-WoM; yang kedua adalah e-WoM negatif dengan motivasi yang ditemukan dalam penelitian ini kurang mendukung kegiatan e-WoM.

Dari penelitian ini tipe Self Satisfaction, Self Enhancement, dan Concern for Other Users merupakan motivasi tipe pengguna Foursquare yang memberikan kontribusi positif terhadap kegiatan e-WoM karena ketiga tipe tersebut secara langsung melakukan semacam rekomendasi atau promosi mengenai tempat mereka check-in. Selanjutnya tipe Feature Involvement, Advice Seeking, dan Economic Incentives merupakan tipe yang kurang memberikan kontribusi positif terhadap kegiatan eWoM. Namun tipe Advice Seeking dan Economic incentives merupakan tipe yang paling merasakan manfaat dari kegiatan e-WoM melalui Foursquare ini. Sedangkan tipe motivasi Feature Involvement merupakan tipe yang paling tidak berkontribusi terhadap kegiatan e-WoM dan paling tidak merasakan manfaat dari kegiatan e-WoM melalui Foursquare ini.

\section{Implikasi Manajerial}

Tujuan dari penelitian ini adalah untuk mengekplorasi motivasi pengguna Foursquare dengan melakukan check-in di tempat-tempat mereka berada. Dengan check-in secara tidak langsung pengguna tersebut telah melakukan kegiatan e-WoM baik secara sadar maupun tidak disadari. Dengan menggunakan 60 responden sebagai sumber informasi dan pengumpulan data, maka hasil penelitian menemukan berbagai macam tipe-tipe pengguna Foursquare dan berbagai macam motivasi yang mendorong para pengguna Foursquare tersebut.

Berdasarkan hasil studi awal tersebut maka diketahui bahwa e-WoM ini efektif dilakukan oleh pengguna dari Tipe The Mayor, The Show-off, dan The Angels. Ketiga tipe tersebut melakukan kegiatan e-WoM yang positif yang secara langsung dan tidak langsung merekomendasikan tempat mereka berada. Sedangkan tipe The Need Help merupakan tipe yang paling merasakan manfaat dari eWoM ini, sehingga pengguna Foursquare yang paling merasakan manfaat dari fitur-fitur Foursquare adalah dari tipe The Need Help. Oleh karena itu, bidang usaha yang ingin memanfaatkan Foursquare sebagai salah satu media marketing dapat menyasar program-program marketing-nya dengan memberikan program kepada tipe The Need Help, The Mayor, The Show-off, dan The Angels.

Tipe The Need Help, tipe ini merupakan tipe yang bergantung pada rekomendasi dan pengalaman dari pengguna Foursquare lainnya. Tipe ini menggunakan Foursquare sebagai salah satu sumber informasi dan referensi yang dianggap cukup akurat. Sehingga salah satu tipe yang harus diberi perhatian lebih adalah tipe The Need Help ini karena tipe ini merupakan tipe yang paling merasakan manfaat dari e-WoM melalui media Foursquare ini. Tipe The Mayor merupakan salah satu tipe yang dapat dikatakan adalah customer yang paling loyal terhadap suatu tempat tertentu karena pengguna yang menjadi Mayor suatu tempat (venue) merupakan pengguna Foursquare yang paling 
sering check-in di tempat tersebut. Oleh karena itu tipe The Mayor merupakan salah satu pelanggan paling loyal. Kemudian tipe The Show-off merupakan tipe yang menggunakan Foursquare untuk memberitahukan kepada pengguna lain tempat-tempat istimewa yang mereka kunjungi. Oleh karena itu jika pebisnis mampu memberikan program marketing yang menjadikan tempat bisnisnya suatu tempat yang istimewa atau unik untuk tipe ini, tipe ini akan memberikan respons positif. Terakhir adalah tipe The Angels merupakan tipe yang selalu memberikan tips-tips dan saran setiap kali check-in di suatu tempat. Sehingga jika pebisnis mampu memberikan program marketing yang baik dan menarik, tipe The Angels akan meninggalkan tips-tips yang baik dengan memanfaatkan Foursquare. Namun karena tipe ini merupakan tipe The Angels, jika program marketing yang diberikan kurang menarik, produk atau pelayanan kurang baik, tipe ini juga akan meninggalkan tips-tips yang kurang menguntungkan pebisnis.

\section{Keterbatasan Penelitian}

Keterbatasan yang dihadapi dalam penelitian yang menggunakan eksplorasi kualitatif adalah pada saat pelaksanaan responden diminta kesediannya untuk diwawancarai sambil menggunakan Foursquare. Sedangkan Foursquare digunakan untuk check-in di lokasi tertentu sesuai dengan keinginan pengguna untuk check-in, sehingga peneliti harus dapat menentukan saat dan tempat yang tepat ketika pengguna ingin check-in dengan menggunakan Foursquare. Pada saat interview responden juga pada keadaan sedang berada di luar (seperti kampus, mall, restoran, dll), sehingga responden agak keberatan karena merasa sedikit terganggu dengan interview ini. Untuk penelitian yang akan datang, akan sangat baik jika dibuat perbandingan antara pengguna Foursquare di kota-kota besar lainnya, seperti: Surabaya, Bandung, Semarang, Yogyakarta, dan Medan dengan menambah responden dalam jumlah yang lebih mewakili populasi.

\section{DAFTAR PUSTAKA}

Balasubramanian, S. and Mahajan, V. (2001). The Economic Leverage of the Virtual Community. International Journal of Electronic Commerce. Vol. 5 No. 3, pp. 103-138.

Cakim, I. M. (2010). Implementing Word of Mouth Marketing. New Jersey: John Wiley \& Sons.

CreasionBrand. (2011). Menciptakan Penjualan Melalui Sosial Media. Jakarta: Elex Media Komputido.

Dichter, E. (1996). How Word-of-Mouth Advertising Works. Harvard Business Review, 44 (November-December), pp. 147-166.

Elcom. (2011). Foursquare Jejaring Sosial Berbasis Lokasi, Mainan Baru Ranah Maya. Yogyakarta: Andi.

Engel, J. F., Blackwell, R. D. and Miniard (1995). Consumer Behavior. Florida: Dryden

Foursquare Labs. (2012, Jan). www.foursquare.com.

Goldsmith, R.E. (2006). Electronic word-of-mouth, in Khosrow-Pour, M. (Ed.), Encyclopedia of ECommerce, E-Government and Mobile Commerce, pp. 408-12. Hershey, PA: Idea Group Publishing.

Hasan, A. (2010). Marketing dari Mulut ke Mulut. Yogyakarta: MedPress. 
Hennig-Thurau, T., Gwinner, K. P., Walsh, G. and Gremler, D. D. (2004). Electronic word-of-mouth via consumer-opinion platforms: what motivates consumers to articulate themselves on the Internet? Journal of Interactive Marketing. Vol. 18 No. 1, pp. 38-52.

Kelleher,C., and Helkkula, A. (2010). Virtually Speaking-Costumer to Customer Communication in Blogs. Journal of Applied Management and Entrepreneurship. Vol.15, No. 3.

Kotler, P. and Armstrong, G. M. (2008). Principles of Marketing. $12^{\text {th }}$ Edition. New Jersey: Prentice Hall.

Maulana, A. (2009). Consumer Insights via Ethnography: Mengungkap yang Tidak Pernah Terungkap. Erlangga: Jakarta.

Schiffman, L. G. and Kanuk, L. L. (2000). Consumer Behavior. New Jersey: Prentice Hall.

Shinnar, S.R., Young, C.A., and Meana, M. (2004). The Motivations for and outcomes of Employee Referrals. Journal of Business and Psychology. Vol. 19, No.2.

Sundaram, D.S., Mitra, K., \& Webster, C. (1998). Word-of-Mouth Communications: A Motivational Analysis. Advances in Consumer Research, 25, pp. 537-531.

Swarbrooke, J. and Horner S. (2007). Consumer Behavior in Tourism. $2^{\text {nd }}$ Edition. London: Routledge. 